This item was submitted to Loughborough's Research Repository by the author.

Items in Figshare are protected by copyright, with all rights reserved, unless otherwise indicated.

\title{
Elite female soccer players' dual career plans and the demands they encounter
}

PLEASE CITE THE PUBLISHED VERSION

https://doi.org/10.1080/10413200.2020.1716871

PUBLISHER

Taylor \& Francis

VERSION

AM (Accepted Manuscript)

PUBLISHER STATEMENT

This is an Accepted Manuscript of an article published by Taylor \& Francis in Journal of Applied Sport Psychology on 30 Jan 2020, available online: http://www.tandfonline.com/10.1080/10413200.2020.1716871.

LICENCE

CC BY-NC-ND 4.0

\section{REPOSITORY RECORD}

Harrison, Grace E., Emma Vickers, David Fletcher, and Guy Taylor. 2020. “Elite Female Soccer Players' Dual Career Plans and the Demands They Encounter". Loughborough University.

https://hdl.handle.net/2134/14223998.v1. 
Elite Female Soccer Players' Dual Career Plans and the Demands they Encounter

Grace E. Harrison

Loughborough University and Talented Athlete Scholarship Scheme

Emma Vickers

Talented Athlete Scholarship Scheme

David Fletcher

Loughborough University

Guy Taylor

Talented Athlete Scholarship Scheme

Author Note

Grace E. Harrison, School of Sport, Exercise and Health Sciences, Loughborough University, United Kingdom and Talented Athlete Scholarship Scheme, Newcastle Upon Tyne, United Kingdom; Emma Vickers, Talented Athlete Scholarship Scheme, Newcastle Upon Tyne, United Kingdom; David Fletcher, School of Sport, Exercise and Health Sciences, Loughborough University, United Kingdom; Guy Taylor, Talented Athlete Scholarship Scheme, Newcastle Upon Tyne, United Kingdom.

Correspondence concerning this article should be addressed to Grace E. Harrison, Talented Athlete Scholarship Scheme, College House, Northumbria University, Newcastle Upon Tyne, Tyne \& Wear, NE1 8ST. Email: grace.harrison@tass.gov.uk

The authors confirm that the data supporting the findings of this study are available within the article [and/or] its supplementary materials. 


\begin{abstract}
An increasing number of female soccer players are playing at the elite level. It is important to encourage these players to remain mindful of the benefits of carrying out a dual career (e.g., higher education and elite sport path). The current study provides an investigation of players' dual career plans and the demands they encounter. The guiding framework used within the research was the Push-Pull theoretical framework. Semi-structured interviews were conducted with eleven participants, encapsulating a variety of players at differing stages of their academic/vocational development. The data were analysed using thematic analysis. All but one player in compulsory and secondary education were found to have a desire to carry out higher education, with three of these players planning to attend university in America. The main reason given by players for planning to continue education was to 'have something to fall back on'. Dual career difficulty was found to increase as players' level of education increased (i.e. from school to university and from university to vocation). Suitable support systems (e.g. university support, family support) were found to play an integral role in the dual career demands faced by participants, with players receiving varying levels of support from their educational institutions and soccer clubs. The current paper advances previous work on the dual careers of athletes, focusing specifically on English women's soccer during a period of key change within the governing body.
\end{abstract}

Keywords: education, The FA, female soccer players, student-athlete, dual career

\title{
Lay Summary
}

We explored the decisions of and demands faced by female soccer players as they strive to combine work/education with their sporting commitments during a time of a change within The Football Association. Female soccer players were found to experience differing levels of support from their educational provider and soccer clubs. 
Elite Female Soccer Players' Dual Career Plans and the Demands they Encounter A dual career, defined as the integration of a sporting career with education or work, provides athletes with a number of benefits both during and following retirement from elite sport (European Commission, 2012; Duty of Care in Sport Review, 2017). For athletes immersed in an elite sport environment, a dual career can provide numerous benefits at the social (e.g. expanded social support systems), health-related (e.g. more balanced lifestyle), developmental (e.g. development of multiple identities), and financial (e.g. enhanced future employment prospects; Reints, 2011) levels. For athletes that choose to pursue a dual career, the balance of elite sport and academic study can be challenging (Vickers, 2018). Athletes not only face athletic and academic/vocational demands, but are also challenged at the psychological, psychosocial, and financial levels (Wylleman, \& Lavallee, 2004; De Brandt, 2017). Despite these multiple demands, it is possible for dual career athletes to achieve a balanced lifestyle. This is possible through the possession of necessary dual career competencies (e.g. dual career management, career planning, emotional awareness, and social intelligence \& adaptability), in addition to having suitable support structures and arrangements in place (De Brandt, 2017; De Brandt, Wylleman, Torregrossa, Defruyt, \& Van Rossem, 2017; Li \& Sum, 2017). The experiences of athletes within the dual career setting are impacted by micro (e.g. individual athlete characteristics), meso (e.g. parents, peers, teachers, coaches), macro (e.g. education institutions, national governing bodies, governments), and global (e.g. international governing body) factors (Condello, Capranica, Doupona, Varga, \& Burk, 2019). Strong relationships, open communication, and flexibility between the aforementioned stakeholders can have both direct and indirect impact upon athletes' dual career experiences (Condello et al., 2019; European Commission, 2012; Fuchs et al., 2016; Gledhill \& Harwood, 2015). 
An example of collaboration between the micro, meso, and macro levels is the US National Collegiate Athletic Association (NCAA). Within the NCAA, intercollegiate athletics are integrated into higher education, where both the educational and sporting experience of student-athletes are a focus at the organisational level. This is highlighted through collegiate environments, where sports and study are accessed on one site (Meyer, 2005; NCAA, 2018). A prominent feature of the NCAA system is that it forms part of the talent pathway for professional sport. Within the UK context, the 2018/19 season saw a change in the English Football Association's (The FA) league structure, making it compulsory for all Women's Super League (WSL) teams to be full-time and professional. In additional to the changes at the senior level, The FA recently developed Women's Super League Dual Career Academies. The WSL Dual Career Academies, developed in 2018, have seen WSL clubs paired with a further education institution and local university. It is compulsory for players within these WSL Academies to be undertaking an education or vocation alongside their soccer commitments. This is considered to be a step towards building a dual career system for women's soccer in England (BUCS, 2018).

Despite the increasing professionalism of the women's game, it remains important for players to follow a dual career pathway. As way of comparison, there still remain a number of differences between male and female players within and following retirement from soccer. First, there is a significant difference in pay between male and female players. Players in the WSL, the highest league of women's soccer in England, earn an average of $£ 26,752$ a year, while men in the male equivalent Premier League, receive an average of $£ 2.64$ million (Sporting Intelligence, 2017). Second, research has found fewer female than male players were able to transfer their skills into well-paid coaching and administration roles after they retire from the sport (McCormack \& Walseth, 2013). These factors highlight that postretirement financial security is not probable or guaranteed for these female players. This 
emphasises the importance of players engaging in a dual career, preparing vocationally and financially for the future, as well as reaping the benefits that players can experience during the dual career process (e.g. expanded social support networks; Day-Garner, 2017).

Within the dual career literature, research has focused upon the transitional experiences of athletes from secondary to higher education (Brown et al., 2015; MacNamara \& Collins, 2010; Wylleman \& Rosier, 2016). Research by Ryba, Stambulova, Ronkainen, Bundgaard, and Selänne (2015) and Defruyt et al. (2019) has looked prospectively at athletes' future transitions. These papers outlined the motives behind athletes' transitional decisions, focusing specifically on the transition into higher education. With professional women's soccer on the rise, it is important to explore players' specific dual career plans with regards to future vocational careers, as well as education. The rationale and motivation behind a player's dual career decision is likely to impact upon their experience within the dual career environment (Lupo et al., 2014). This makes the prospective decision-making process an important area of consideration.

This research focused upon soccer players within the Women's FA. The recent organisational changes make women's soccer a particularly interesting and fruitful area of study. Part one of this research focused upon the prospective aspect of players' dual careers. The research investigated the future dual career plans of elite women's soccer players, with a focus upon the transitional plans of those players aged 18 and under. The guiding framework used within part one of the research was the Push-Pull theoretical framework (Schultz et al., 1998; Fernandez, Stephan, \& Fourquereau, 2006; Defruyt, Wylleman, Kegelaers, \& De Brandt, 2019). The Push-Pull framework explores the thought processes individuals will follow when considering a specific decision. In the context of this research, the framework allows for dual career decision making processes to be divided into four quadrants: (a) pull factors, the perceived positive aspects of carrying out a dual career, (b) anti-pull factors, the 
perceived risks and costs of carrying out a dual career, (c) push factors, the negative considerations of only playing soccer, and (d) anti-push factors, the deterrent factors that discourage players from carrying out a dual career (i.e. desire to just play soccer). This framework adds depth to players' decision-making processes, outlining variables that influence players' decisions. The framework determines the incentives and deterrents of players carrying out a dual career. The use of the Push-Pull framework may also allow for comparison between athletes perceived dual career expectations (push and pull factors) and athletes lived dual career experiences (Defruyt et al., 2019). The outcomes of this research are of particular importance to the domain of dual careers. By considering dual career plans more broadly, this research assesses how development within the women's game is impacting upon players' dual career aspirations. The findings increase understanding of the push and pull factors that attract or detract female soccer players from pursuing an educational or vocational dual career following further education.

Part two of this research focused upon the dual career demands faced by elite female soccer players aged between 16 and 22 years. It is important to distinguish between the different dual career paths that individuals can take, balancing sport and educational/ vocational development at different levels (Cartigny, Fletcher, Coupland, \& Taylor, 2019). As outlined by Stambulova and Wylleman (2019), the dual career literature is predominantly focused upon student athlete populations. The review also highlighted a need to further explore dual careers in sport and work. The novelty of this research is that it investigated the dual career demands faced by athletes in different career stages of the same sport. Players in the sample ranged from those who recently completed their General Certificate of Secondary Education (GCSE) examinations, to those in full time employment. This research will help to generate information on what can be implemented with the next cohort of athletes to ensure that support at the meso, macro, and global levels reflects the needs of the players. 
Accordingly, the first aim of the current study was to understand elite female soccer players' future dual career plans. The second aim was to examine the dual career demands encountered by elite female soccer players at various developmental stages within education/vocation and within soccer. Third, the research aimed to assess what macro and global systems can do to encourage players to follow a dual career pathway.

\section{Methods}

\section{Research Design}

The approach to inquiry taken within the research was constructivism, manifested through a subjective ontology and relativist epistemology (Lincoln \& Guba, 2000). This research centered primarily upon the dual career demands faced by participants. The research delved into the perceptions and feelings of those players who experience life as dual career soccer players. The constructivist approach enabled the researchers to develop an essence of dual careers, providing a holistic and detailed understanding of the subjective meanings that correspond to participants' experiences. The design and analysis of this research were aligned with the researchers' philosophical view, acknowledging that individuals develop subjective meanings of their experiences (Creswell, 2013). As a result an exploratory approach, based on qualitative research, was used to investigate the dual career plans and demands encountered elite female soccer players. When exploring these demands, qualitative methods are particularly valuable, providing a holistic and comprehensive clarification of athletes' own perceptions (Li \& Sum, 2017). The use of semi-structured interviews was appropriate for this specific research question. This was due to the variety of participants included within the research and the type of information being gathered. Each participant's plans and demands encountered are individual to them. One-on-one interviews provided the platform for these individuals to honestly share their dual career journey and the reasoning behind their future plans (Bauer \& Gaskell, 2000). 


\section{Participants}

Participants in this study included eleven purposefully sampled elite female soccer players, ranging in age from 16 to 22 years $(\mathrm{M}=18, \mathrm{SD}=2.21)$. Table 1 provides an overview of participant characteristics, including: age, soccer level, educational level, and dual career plans. The use of intense and purposeful sampling enabled information-rich cases to be studied. This provided detailed insight and understanding of participants' dual career plans and the demands they encountered (Patton, 2002). The study encapsulated a variety of participants, with dual careers ranging from the combination of soccer with GCSE studies, General Certificate of Education Advanced Level (A-Level)/International Baccalaureate studies, university studies, and full-time employment. Using Swann, Moran, and Piggott's (2015) model of classification of expert performance as a guide, the participants within this study ranged from competitive elite to successful elite performers.

\section{Participant Recruitment}

A selection of participants were recruited through the Talented Athlete Scholarship Scheme (TASS), a Sport England funded partnership that supports athletes in education. Due to data protection, initial communications with potential participants'/participants' parents (for those under 18 years) were carried out through TASS via email. The remaining participants were recruited through direct contact with eligible individuals via social media platforms.

\section{Data Collection}

Athletes interested in participating were asked to contact the lead researcher directly via email. A document containing a participant/parental information sheet and consent form was then forwarded onto athletes/parents to be completed prior to any interview taking place. Once athlete/parental consent was granted, a suitable interview time was discussed. Interviews were conducted by the lead researcher and were carried out via telephone and 
video chat devices (e.g., Skype). This allowed a varied and purposeful sample to be reached in a time efficient manner (Lo Iacono, Symonds, \& Brown, 2016). Each interview began with an explanation of the research and the interview process, followed by the assurance of confidentiality and the participants right to withdraw at any time. Participants then had the opportunity to ask any questions regarding the research. With participants' consent, all interviews were digitally recorded. The interviews lasted between 25 and 35 minutes $(\mathrm{M}=$ $30, \mathrm{SD}=3.49)$. The interviews were carried out during participants' intensive pre-season training, limiting the time players had available to participate. Research has found telephone interviews to be relatively shorter than face-to-face interviews yet generating concise and rich responses directly focused upon the research question (Oltmann, 2016; Vogl, 2013).

Guided by previous dual career literature (e.g., O’Neil, Allen, \& Calder, 2013; Stambulova, Engström, Franck, Linnér, \& Lindahl, 2015), four interview guides were developed, tailored specifically towards athletes' differing levels of education. Throughout each interview guide the questions were broad and general, enabling participants to construct meaning from the situation they were asked to discuss. A thread running throughout all interviews was a focus upon individual's soccer and academic journeys, sources of support, psychological development, financial demands, and dual career demands. The remaining questions had a specific focus dependent upon player's current level of academic study. To expand, for players who had recently completed GCSE studies, questions were focused upon their upcoming plans with regard to academics. For those who were completing or had recently finished A-Level/International Baccalaureate studies, the focus was upon their plans as they transition away from school/college. Players who were currently at university or had recently completed further education studies, received questions focused upon comparing the dual career demands at school to those at university. These players were also asked to retrospectively discuss their pre-transition decisions/expectations and prospectively discuss 
any future education or vocational plans. Finally, for players who were in full-time employment, the focus was upon the dual career demands of balancing soccer and work, comparing these demands to those whilst at school/college.

\section{Data-Analytic Strategies}

The data was analysed using Braun and Clarke's (2019) six-phase framework of thematic analysis. All interviews were transcribed by the lead researcher. This allowed the researcher to become immersed in the data, generating initial ideas and becoming familiar with the content of each interview. Each interview transcript was then coded using a colourcoding system. This identified interesting features or repeated patterns within the data. Following prolonged engagement with the data, the codes were then collated into two separate sets of sematic level themes and sub-themes. The first set of themes related to participants' dual career plans. The second related to the dual career demands faced by participants. This stage of analysis enabled the researcher to compare and contrast key plans and demands from one participant to another (Sparkes \& Smith, 2014). A thematic map of the analysis was then generated, allowing the themes and sub-themes to be reviewed and revised. This ensured that the generated themes worked towards addressing both parts of the research question (Braun \& Clarke, 2019). The themes were then defined, and specific extract examples were selected in order to most effectively support the findings. The analysis was driven by the research question, providing rich and detailed accounts of participants' future plans and experienced demands (Braun \& Clarke, 2019). The process of thematic analysis was inductive, with diverse coding and generated themes linked specifically to the data rather than the researcher's theoretical interest. This allowed for more rich description of the information generated from the interview process (Braun \& Clarke, 2019).

\section{Methodological Integrity}


Following recommendations by Levitt, Motulsky, Wertz, Morrow and Ponterotto (2016), a number of processes were followed to increase the methodological integrity and consequently the trustworthiness of this work. Fidelity to subject matter and utility in achieving goals were of key concern throughout the design, data collection, and data analysis of this research (Levitt et al., 2016). First, data was collected from diverse sources, encompassing players of differing levels academic and soccer development. This effectively represented the variation within the phenomenon of dual careers. Second, reflexivity on the part of the researchers was an integral part of the research process. There was continual selfreflection of the ways in which the researchers may have impacted upon the investigation and the generated findings (Sparkes \& Smith, 2014). Despite having no previous involvement or connections within the soccer, the lead researcher has spent a number of years immersed in a dual career environment. This may have elicited bias towards data that confirms the lead researcher's knowledge of the benefits of engaging with a dual career. Continued selfreflective journaling was conducted in order to understand and embrace this bias. This provided a clearer understanding of the reasons for the lead researcher's interpretations. Researcher reflexivity allowed a more sincere representation of participants' dual career plans and demands to be portrayed. This increased the credibility and confirmability of the research (Tracy, 2010; Shenton, 2004).

With regards to transferability, sufficient contextual information was provided by the researcher. This information included: detail regarding the number of participants, the soccer and academic level of these participants, the methods of data collection, and the length of interviews (Sparkes \& Smith, 2014). This information allows readers to consider the findings within their appropriate context and assess whether the results from this investigation can be applied to their own experiences (Shenton, 2004). The data collected provided ground for insightful analysis, with meaningful findings pertaining to elite female soccer players' future 
dual career plans and dual career demands, shedding light on a previously under-researched area.

\section{Results}

The results will be presented in two-parts, aligned with the two separate research questions. Section one will report on the findings relating to participants dual career plans. Players' prospective dual career plans will be presented based on the adapted Push-Pull theoretical framework (Schultz et al., 1998; Fernandez et al., 2006; Defruyt et al., 2019). Section two will report on the dual career demands faced by participants. The varying factors that influence female soccer players dual careers will be presented. A comparison of dual career demands at differing stages of academic/vocational development will also be outlined (i.e. school, university, and vocational level demands).

\section{Section One: Dual Career Plans}

Pull factors. Six out of the seven participants who were in compulsory or further education had a desire to continue their education at university. A number of pull factors were identified as encouraging players to follow the dual career route.

Importance of dual careers. Knowledge of the importance of education was a predominant factor that impacted upon players pull towards carrying out a dual career. Although the importance of education was understood well by players, parents, and soccer staff, education was continually labelled as a 'back up plan'. The following quote from participant eight highlights the importance of education from the perspective of her WSL development squad coaches:

In terms of soccer, I think they are very flexible with education, they [club coaches] always say that education should come first because there needs to be a back-up plan because only like 1 or 2 of you are going to make it from this group of players, so you need to have a back-up plan. 
Similarly, the following quote highlights the need to engage in a dual career from the perspective of participant one:

I'd say my parents are massive in all my decisions. They never forced me to do anything, they never forced me to go to uni, but they helped me be very realistic that like, it is a soccer career at the end of the day, it is not guaranteed, but also it is women's soccer so you do need education for a secondary career.

Players also highlighted 'getting education done and out the way' as a pull towards education in the short term. These players acknowledged the importance of continuing education at university and gaining a degree, whilst also appearing to see education as a tick-box exercise. For these players, their plan was to pursue a full-time soccer career following graduation. The following quote highlights the 'get it done' approach to participant one's undergraduate degree:

I did think about having a gap year but definitely now, the way it is, I use to be fine working, like I used to find it easy but I could just smash out the hours. But now I have got a taste of training full time I do find it difficult to apply myself academically because I am soccer motivated mostly. But that's why I'm glad I didn't take a gap year, because I think it would have been even harder for me to go back and do it, so I'm kinda like steam-rolling my way through it.

The previous three quotes highlight a pull towards continuing education, with players planning to pursue a dual career as a back-up plan for life after soccer. It is important for players, parents, and club staff to understand the many benefits a dual career can provide in addition to future employment prospects.

Soccer club-university partnerships. The pairing of WSL clubs and universities was known amongst participants. This acted as a pull towards players continuing education within one of these partnerships. Despite a number of players not appearing to be well informed of 
the details of these partnerships, the majority of players believed they would make use of this new development from The FA. The following quote highlights participant three's intention to make use of these partnerships in the future:

Well, recently there has been something introduced with some universities, I think Nottingham is one of them and I think Liverpool might have something to do with it. Where the club is trying to link into the university or something like this. So I'd probably do that, but I've not really thought about it too much.

The above quote highlights that players had an awareness of such partnerships, however, they still have limited knowledge around exactly what they entail. It is important for players to be directed towards sources of information regarding these partnerships, enabling players to make an informed choice of whether or not this would be the best option for them.

University in America. Finally, a pull towards engaging in a dual career was the opportunity to attend university in America. Players within the research had a desire to attend university in the US, with the large investment into supporting student-athletes acting as a key pull factor in this decision. The following quote highlights the incentives of studying in the US, encouraging participant ten to carry out her dual career in America:

From what the [US collegiate] coaches tell me, they all say the same thing, saying they have all the support you need if you are struggling, they have academic counsellors who will help. I think there is a lot of money invested into it so they have a lot of help everywhere.

Participant nine, a student at university in the UK, also mentioned the US system and the greater focus placed upon student-athletes:

In America, student-athletes are way bigger than they are in the UK. If it [UK system] could just work towards something like that maybe, more uni sport, uni and soccer combined, that'll be a step in the right direction. 
The above two quotes highlight players' perspectives of the US system, with factors that push players away from education in the UK and pull players towards continuing education in the US. The pull towards the US was highlighted by participant two who discussed the increasing number of players making the move to study in the US: "I think there are a lot of older players at [club] and England who have gone to America, so it is quite a common thing”.

An interesting finding regarding the pull towards the US, is a lack of communication between players and managers/coaches at their club/England regarding the possible move. Participant two outlined the barriers she faced in communicating her potential move to the US with coaching staff at her club and at England:

Club and England [coaching staff] wouldn't be happy about it, so we didn't talk to any of them about it... They are definitely not happy about the amount of people that are leaving. Most people don't tell [club] or England [coaching staff] until like right before they go. But we just said it like it's a plan B if it doesn't work out at [club] then I'll go but for me I'm probably just going to go anyway.

The above quote from participant two highlights the concerns that players have about expressing their plans with their coaches, particularly when these plans include relocation to the US.

Anti-pull factors. Throughout the sample, players identified very few anti-pull factors, with low perceived risks and costs of carrying out a dual career. Players within the sample did, however, mention a couple of anti-pull factors that are important to discuss.

No enjoyment of academics. Contrasting from the majority of players within the sample, some players faced the anti-pull factor of not enjoying academics. Despite knowledge of the importance of education, these players struggled academically and didn't enjoy school. For these players, all attention was directed towards their soccer ambitions, as outlined in the following quote from participant four: 
I am not academic at all, like really not at all, so I struggle with that because I'm really not academic... I know you need to have something to fall back on, but I have always just pushed soccer because I'm not academic, I've just kind of really pushed my soccer.

For players such as participant four, continuing traditional education (i.e. further or higher education) may not be the most suitable route. It is important to highlight that a dual career can also include vocational qualifications (i.e. apprenticeships), which may be better suited to some individuals.

Lack of university options within the club-university partnerships. Despite the pull factor of club-university partnerships as discussed above, some players did struggle with the limited choice of universities involved within the partnerships. The following quote from participant five highlights this challenge:

I think a big starting place when I was picking unis was seeing where there was local clubs that linked to it... I think several centres were set up around the place that were supposed to support soccer, but I felt the universities weren't really the one's for me. So maybe spreading that support out over the other unis might be more useful. The suggestion of increasing the number of club-university partnerships may allow more players to follow their desired academic route alongside playing soccer.

Push factors. The older players within the sample (i.e. two players who were in/seeking employment and two players who were currently undertaking undergraduate degrees) discussed push factors towards pursuing a dual career. These push factors came from negative considerations of only playing soccer.

Injuries. Injuries were highlighted by players as key push factors towards a dual career. This was outlined by participant nine who was currently in her first year of university: 
I think the fact that I've had quite a lot of injuries even though I'm only 19. So I just needed to make sure that if I did get injured and it was like quite a bad one, then I need a degree to fall back on. So it was just that little bit in your mind that you don't know what could happen in the next 5-10 years, so I just wanted to carry on, get a degree, it is only 3 years worth of work, and make sure that I could always fall back on that really.

For players such as participant nine, injuries highlighted the lack of security that a sporting career provides. This further emphasised the importance of gaining a degree and developing educationally outside of sport.

Difficulty of making a living out of soccer alone. Participants six and eleven who were currently in/seeking employment, faced the difficulty of making a living out of soccer alone. Participant eleven highlighted the necessity to have an alternative career in the following quote:

I'd still like to play soccer, but there is not enough money in soccer to do anything. You have to just be in soccer these days because you like it, there isn't enough money to make a career... It's hard trying to earn a full-time living, like covering the bills and stuff. I need to quit at some point and get a career started going. This quote outlines one of the key challenges faced by female soccer players at the Championship level. Although these players may earn a small income playing semiprofessional soccer, this money is not enough to sustain their soccer career without a need for additional employment. These players are having to put their dream of a full-time soccer career on-hold in order generate additional income.

Anti-push factors. A number of players within the sample discussed the same antipush factor, discouraging them from undertaking a dual career at this present time or in the future. 
Desire to play soccer professionally. The predominant anti-push factor identified by players within the sample was the desire to play soccer and achieve goals within the sport. Despite the collective understanding of the importance of education, participants had a strong desire to play soccer professionally for club and country. Some players within the sample planned to defer their entry to university, devoting a year to train and work towards achieving goals within soccer. Participant five explained her decision to take a gap year:

I'm going to have a gap year this year, commit to playing full-time soccer and just see where it takes me... I felt like this year I hadn't really given soccer much of a chance because I've been focusing on my A-Levels. So I thought give it a year just to see how far I can get in the age groups and see if I can get a few more experiences in there.

Participant five had, however, applied to universities deferring entry for one year. This shows a commitment to continuing her dual career following a year of solely focusing upon soccer. A selection of dual career participants discussed their plans to leave education once they had gained their qualifications in order to focus upon soccer. Participant one outlined her plans following completion of her undergraduate degree:

I'm aiming to try and get a first and then my plan at the moment is to leave education while I'm playing soccer. So just focus on soccer for however many years and then definitely after soccer or towards the end of my soccer career, I plan to get back into education.

The above quote highlights participant one's desire to step away from soccer following graduation. Despite the initial termination of her dual career, the plan to return to education is a promising step in furthering her personal and professional development in the latter stages of her soccer career.

\section{Section Two: Factors that Influence Female Soccer Players Dual Careers}


Soccer specific dual career demands. Throughout all interviews, emphasis was placed upon the difficulty of balancing a dual career. Results suggest that a dual career became increasingly difficult to manage as players level of education increased. For example, participant one described the balance of elite soccer and GCSE level studies as not too difficult: “Up until and including year 11 I was playing for [club] but it wasn't too difficult, like I could manage it, balancing school and soccer... so I think I got 12 GCSEs in the end". Alongside the progression into further education, a number of players balanced club training with England age-group squad commitments. These players had to regularly attend training camps and tournaments, exacerbating the demands faced by players at this stage. Participant two outlined the amount of time she was absent from school during her first year of ALevels:

It is hard, especially this year, because there were so many England camps. Like I missed 3 weeks of school at one point and my attendance ended up being about 30 or $40 \%$ throughout the year because I missed so many lessons.

Players in higher education also faced the complexity of missing time in education, with seemingly greater difficulty. The following quote highlights the challenges faced by participant one:

Well it was a bit of a shock to the system [transitioning from school to university] because I train full time, so the whole year I never really went to any lectures, I did distance learning, so it was a shock to the system. The entire year I felt like I was playing catch up the whole time, because I'd miss a lecture then I'd have to catch up, but in the time that I'd caught up there would be another one and I never really got up to date.

An additional challenge faced by players in higher education was the difficulty of training full-time with players who were not currently in education. Participant nine 
discussed how she compared her dual career schedule with the differing commitments of her teammates:

When I got to [club], there is a lot of older players, some of them have been there, done that and have got a degree, it's just because they are older they are now just fulltime. Some of them never went to uni, so there is a big difference, when they leave soccer they go home and they're off, can do whatever they want, whereas I go home and have to do uni work, that's the difficult part.

Participant six, a player in full-time employment, highlighted the extreme difficulty she faced when balancing semi-professional soccer and a full-time job. The challenges she faced led her to eventually make the transition away from semi-professional soccer back to the amateur level:

With college you know you could take the days off...but then when I got the full-time job at the gym and I started doing the apprenticeship there, that is when my soccer had to obviously take a back seat, because I was in full-time work then, and that's what was paying the bills at the end of the day so I just needed to prioritise. I mean my [work] manager was good, he did try and balance it as much as he could, but there are only certain limits that an employer will do for a hobby at the end of the day. The previous five quotes highlight the differing demands faced by players at varying stages of academic/vocational development. As players progressed from GCSE level, to further education, higher education, and full-time employment, the demands faced by players increased in difficulty.

Support systems. When explaining how they overcome the difficulties associated with balancing a dual career, participants discussed the support systems they have in place. School/university/vocational support. In general, players at the school level were satisfied with the amount of support they received from their school/college. Some players 
received high levels of support from individual teachers within their school environment. Other players discussed their satisfaction with their school support, despite teachers not going over-and-above to provide additional support. The following quote highlights the level of support received by participant two:

The teachers, they like try and plan ahead and give me access to powerpoints and stuff while I'm away, but to be honest they don't really do much. They are very accommodating but I wouldn't say they give extra measures to help.

A key finding at the university level is that support provisions differed, to an even greater extent than at the school level, between different academic institutions. The following quote illustrates the support participant one received at a sport-oriented university:

My uni is really supportive. So my personal tutor is really good and also I'm on a sports scholarship so I have someone I can go to if I ever need an extension or something and he is really really good at just helping me out. So I do get a lot of support from uni.

In comparison, the following quote highlights the differing level of support received by participant eleven who attended a university where the sports programmes have a less integral role:

Uni didn't support that [soccer] because it wasn’t a sports uni, it was just purely academic. So if I said I was going to soccer, it was a bit like well why... I think in the fourth year I tried to change the $3-5$ lecture so I could get to soccer and my lecturer was just like, absolutely not no.

The above quotes highlight the significantly different demands players can have at the university level, solely depending upon the dual career support systems integrated into the university environment. A key consideration that arises from this finding is that players should be supported to make an informed choice of where to study. Consideration should be 
given to players academic and sporting aspirations, alongside the dual career support that an academic institution can provide.

At the vocational level, the employer of participant six was accommodating, striving to provide flexibility whilst working within the restrictions of full-time employment:

It was difficult, but the transition [to semi-professional soccer] did work and I sort of told work that it's my second job really and they understood so they put me on the early shifts; still working full-time but then it allowed me to get to training on time and I was able to go to every session that [club] wanted.

As previously mentioned, it has been found that dual career demands increase as players' level of education/vocation increases. The findings outlined above highlight the importance of support at the educational/vocational level, with players in the sample experiencing both optimal and mediocre support. The support players receive from academic staff/employers can significantly impact upon the demands and challenges faced by dual career athletes.

Dual career provision from club and governing body. Seven out of eleven participants were part of the England age-group squads. The majority of players spoke positively about the education provision provided by England education officers at training camps and tournaments. The following quote from participant ten outlines this support:

England [educational officers] really follow up with the teachers at my school and they ask them to write out what I should be doing and then we get however many hours per day supervised to complete the work. Also, they let me sit tests and stuff, so I have sat a few tests whilst I've been away, so when I come back I'm not overloaded with a bunch of tests that I've missed.

The education provision, provided by the dedicated England education officers, has been of huge benefit to the majority of players that were a part of the England set-up. The demands faced by players when absent from school/college for extended periods of time were found to 
be reduced by: (a) the compulsory on-camp education, and (b) communication between England education officers and players educational institutions.

Differing from England's significant investment in education is the limited educational support directly provided by individual clubs. This finding was consistent among players at both the school and university level. At the school level, player eight described some educational flexibility in the form of optional time away from training for school examination periods. This player did, however, explain the difficulties associated with optional time away from training:

It would have been helpful to go down to even less nights training during GCSEs. Because even though they said you could take a week off, if everyone is in training, then I don't really want to take time off. I wouldn't want to give them a reason to not select me.

Players in both further and higher education described a lack of club awareness (i.e. from managers and coaching staff) regarding the educational demands placed upon them. The following quote from participant nine highlights this from her perspective:

It would be helpful to have a bit more education time at club level, but I don't think they're [coaches] aware of how much work we have to do, so we don't have much support for education. We need a little bit of education time that's compulsory. In additional to the lack of club proactivity regarding education, a number of participants mentioned that they did not actively seek support from their club. Participant three explained that she was unaware of any dual career support available:

I never really asked for education support [from club], so it's not like they [coaches] said no, it's just that it never really came up. But if I did need any extra help, I didn't know if anything was available for me to access. 
It is important for clubs to have clear systems in place, where players understand what support is available, who provides the support, and how they access the support.

At the university level, players explained how they would like to see their club take a more proactive approach to education, incorporating formal education into their daily soccer schedule. Participant nine explained this as follows:

Maybe at club level more education there. So like, so we would have time during the morning, but like there was no formal education really, we'd have like an hour and a half so maybe like that could be for us like an education slot. Because it wasn't compulsory, none of us did it...so maybe that is something clubs could bring in.

Participant six, the player in full-time employment, discussed her club as being understanding regarding her employment outside of soccer. She did, however, explain the repercussions that came as a result of missing training for work commitments:

Well I was at [club] then, when I was working at the gym and you know they [coaches] were understanding. You know, they do have to take into priority that they are not paying you a lot of money and I had a full-time job at the end of the day. It was difficult, if you weren't at training then you didn't get played, so it didn't work hand in hand really.

The above five quotes highlight that a lack of proactive education and vocational support at the club level, can impact upon the dual career demands faced by players at all levels of educational/ vocational development.

Extent of soccer prioritisation. A common theme throughout all interviews was the extent to which players prioritised soccer. These priorities appeared to shift as players moved from the school level, to university level, and then onto employment. The majority of players at the school level explained that they prioritised soccer over their academics. The following quote from participant ten highlights this prioritisation of soccer: 
I would have dropped my IB diploma, and it is still possible if it gets too much, but I won't be dropping soccer over school at any point... Soccer will always come first, I definitely feel that way.

The importance placed upon soccer was found to outweigh the importance of education at the school and further education level. As players moved from further education to university, however, a more equal emphasis was placed upon both soccer and academics. Participant nine explained her ambitions to be successful in both her degree and in soccer:

I wanted to do really well in uni, I didn't want to go there and just pass, you know I still want a first. And then again with soccer, I want to do the best that I can. I just try the best I can to balance and prioritise them both and make sure that I don't forget about the uni side, even though it is quite easy to forget about it.

Moving on from the university to the vocational level, players priorities appeared to shift again. At the vocational level, players faced the difficulty of making a living out of soccer alone. For these players, soccer was a hobby alongside full-time employment and couldn't be a priority. The following quote from participant six explains the necessity to prioritise her employment outside of soccer:

Soccer wasn’t covering my outgoings every month. So my income just wasn't covering my outgoings. So realistically with me having to go back to full-time work, I just couldn't balance being a semi-professional soccer player and doing a full-time job as well. So when I got my new job, I made the decision to come back to [club] and do it amateur. It is a shame, but soccer can't be the priority for me at the minute. These priority shifts appear to have occurred through necessity, rather than through choice. As the dual career demands faced by players increased, the level of priority placed upon soccer decreased. It is likely that this is due to a more apparent reality of life outside of soccer 
for these older players, requiring focus on other areas of life outside of soccer, i.e. generating income through employment.

\section{Discussion}

The findings of this research indicated that female soccer players have and experience both comparable and varying dual career plans and demands. These vary both within and between players of differing levels of educational/vocational development. With regards to dual career plans, participants identified a number of pull factors (i.e. awareness of the importance of education and something to fall back on) and push factors (i.e. the uncertainty of a soccer career) towards carrying out a dual career. For players that choose to continue education, they are faced with the decision of where to go to study. Three of seven players that were planning to go to university had a desire to carry out their further education studies in the US collegiate system. This coincides with current trends that have seen an increasing loss of talented English players to the NCAA. In attempt to tackle this talent loss, The FA has discontinued funding the travel costs of England players at US universities, travelling to the UK for training camps and tournaments (Laverty, 2018). This new policy will impact upon talent availability for the national team, i.e. top players sacrificing national team representation for the four-year duration of their degree in the US. This research has also identified the communication barrier that this change of policy creates. Players were found to refrain from openly discussing plans with their club and/or England. This lack of communication raises concerns, with players losing the support from two key stakeholders during a critical stage in their soccer, academic, and personal development (Knight, Harwood, \& Sellars, 2018).

In order to retain talent, players need to be offered a viable alternative to moving to the US. Players outlined the large investments into supporting student-athletes and the ability to equally combine studies and soccer within one institution as the main reasons for their 
desire to relocate to the US. The creation of club-university partnerships within England is a first step in creating an environment where soccer and academics are combined within one institution. The findings of this research provide the following suggestions on improving the system in England, in order to retain more talent in the country. First, better communication of the system in the UK and the benefits it can have for players. This could be achieved through player workshops, outlining the details of the club-university partnerships and the dual career opportunities they can provide for players. Second, an increase in the proactivity of clubs in supporting and providing necessary flexibility for education. An example of this would be to make it compulsory for all clubs to have a dedicated education/vocational officer or dual career support officer, in order to support players in their dual career. Third, an increase in the education options that are a part of the club-university partnerships. Increasing the number of partnerships would allow more players to follow their desired academic route alongside playing soccer. Forth, further increase the collaboration between clubs and universities within these partnerships. A pull towards the US collegiate system is that players' education and soccer are combined within one institution. Strengthening the clubuniversity partnerships, with minimum requirements for collaborative working, will make the partnerships more desirable and successful. These recommendations highlight key applied implications of this research. These findings can be used by The FA to inform the future development and refinement of the club-university partnerships. Although specific to the English soccer context, the above recommendations are transferrable to other cultural and sporting environments, where key decisions are being made that will inform collaborative dual career systems.

A contrast from the limited support provided directly by clubs, is the education provision provided by The FA at England training camps and tournaments. In 2015, The FA appointed a Player Education Manager and subsequently, Player Education Coordinators. 
Formal education sessions are now a part of the soccer schedule, with two hours of compulsory education for every missed day of school (The FA, 2017). Participants spoke positively of this education provision, particularly the communications between the England Education Manager/Coordinators and players education institutions. These provisions at the macro level, are an example of proactive and successful dual career support. The findings of this research highlight the factors that contribute towards the creation of an effective system of educational support at the governing body level. This research is therefore important in informing governing body dual career provisions for elite athletes in differing sports and countries.

Not all players within the sample had future plans to continue a dual career. These players identified a lack of enjoyment of formal education and the consideration of oneself as 'not academic' as the reasons for this. These players face the challenge of not preparing for life after sport, with the potential of facing negative implications following termination of their soccer career. It is important for such players to be directed towards conducting a dual career via an alternative route (e.g. vocational education). Engaging in more practical education allows these players to continue their personal and professional development outside of soccer, within a context that is better suited to their needs (Capranica \& Guidotti, 2016). This research highlights the importance of conducting subsequent research, investigating the role of non-conventional dual career routes. This would be an interesting area of study, outlining the varying dual career possibilities available for players with differing educational requirements.

Throughout the sample, athletes' support systems were found to be influential in the development of their dual careers, supporting previous findings by Knight et al. (2018) and Tekavc, Wylleman, and Erpič (2015). Flexibility in education is a particularly important component in achieving a sport-education balance (Brown et al., 2015). Within this research, 
participants who attended a sport-oriented university, or a college linked to an academy, had a considerable amount of education support and flexibility. This differed to those participants who attended educational institutions that had fewer sports programmes on offer. Player's choice of where to study can impact upon their dual career experience and their success in both pursuits (Larsen, Alfermann, Henriksen, \& Christensen, 2013). Within the sample, the variation in support and flexibility impacted upon the demands faced by players, as well as the enjoyment and wellbeing in their dual career. It is important for players to be supported to make an informed choice of where to study, with both their education and soccer aspirations in mind. To the researcher's knowledge, no research has highlighted the notable differences in support between educational institutions. Programmes such as the TASS Dual Career Accreditation Scheme, which recognises an education institutions commitment to dual career support (TASS, 2019), are particularly important in supporting informed dual career decision making. This research emphasises the necessity of such programmes in guiding and supporting elite athletes in making informed choices of where to study. This has applied implications for those working directly with elite athletes, using such programmes to guide athletes in their decision making.

With regard to the dual career demands faced by players, a key finding of this research is the more advanced the level of education, the more challenging the dual career becomes (i.e. increasing difficulty from school to university and from university to a vocation). Players at the university level faced additional challenges in both soccer and academic contexts (i.e. increased academic workload, difficulty catching up on missed work, peer influence) than those players at the school level. For players at the vocational level, the challenges further increased. Limited flexibility, increased time commitments, and financial pressures of working in a full-time job, increased the dual career demands considerably. 
The increasing difficulty of balancing a dual career followed the opposite trajectory to players' priority of soccer. Despite players discussing a desire to play soccer professionally, as players level of education/vocation became more advanced, the priority players placed upon soccer began to decrease. Players at the school level prioritised soccer over academics, with players at the university level placing equal emphasis on the two pursuits, and players at the vocational level having to view soccer as more of a hobby. The main consideration for the decrease in soccer prioritisation is a lack of funding and the challenges of making a living out of soccer. This highlights a potential funding barrier to playing at the top level of the sport, particularly for semi-professional players at the Championship level. It is possible that such challenges may eventually lead to a loss of talent within the semi-professional women's game. This research outlines the importance of integrating support structures at all levels of dual career development, with a focus upon increasing the support available to players at the vocational level (Wylleman, De Brandt, \& Defruyt, 2017). It is, however, challenging to tackle the financial barriers to the game, specifically due to the neophyte nature of professional women's soccer.

A limitation of this research is that the sample was made up of players, with no inclusion of soccer, school, or university staff. As mentioned previously, support systems are significant in determining whether or not a player has a positive dual career experience. Including such stakeholders would have helped to provide more depth and insight into this area, generating a more detailed understanding of staff intentions, enabling a comparison to players' perceptions. Future research within the area should include support staff within the sample, enabling the demands faced by players to be further understood within a broader context. A notable strength of this research is that it was sensitive to the changing nature of women's soccer in England, providing a basis for future research to assess the progression and success of these changes. In addition, the findings of this research can inform The FA in 
the continued development of the WSL Academy system; highlighting areas to be improved (e.g. increased proactivity from clubs in supporting education), areas to develop (e.g. increase the number of universities included within the club-university partnerships), and aspects that work well and should be maintained (e.g. the education provision provided at training camps and tournaments). Therefore, this research has the potential to assist in the development of a female soccer environment in England, where players can achieve success in both academic/vocational and sporting pursuits.

\section{Conclusions}

Within the introduction, three key aims of this research were identified. The first aim was to address whether more female players are wanting to step away from a dual career. The findings have highlighted that despite the increasing professionalism of women's soccer, the majority of players prospective plans are to carry out a dual career at the higher education level. The research identified the importance of making an informed choice of where to study, with support structures at the educational level impacting upon the demands faced by dual career players. These findings advance knowledge in the area of dual careers by emphasising the importance of athletes' choice of where to study. Dual career providers can use these findings to best support athletes in their decision-making processes. The second aim was to examine the dual career demands faced by elite female soccer players at various developmental stages within education/vocation and within soccer. This research highlighted the increasing demands faced by players as their level of education/vocation becomes more advanced. The research also identified a decrease in the priority players placed upon soccer from school/college to university, and from university to a vocation. This is new knowledge in the area of dual careers, identifying the unique challenges faced by dual career athletes within employment. This highlights a need to further research this area of dual careers, ensuring that all athletes have the opportunity to thrive in both sport and in employment. The 
final aim of the research was to assess what macro and global systems can do to encourage players to follow a dual career pathway. This research investigated the systems within women's soccer in England, identifying numerous ways in which the pull factors of a dual career can be strengthened. A unique challenge faced by The English FA, is not only encouraging players to follow a dual career pathway, but also convincing players to remain within the country. This research presents novel and interesting findings that provide a detailed insight into English female soccer players dual career plans and the dual career demands encountered by these players. The findings of this research have a wealth of applied implications for informing future policy, practice, and research. 


\section{References}

Bauer, M., \& Gaskell, G. (2000). Qualitative researching with text, image and sound: A practical handbook for social research (1st ed.). London: SAGE Publications Inc.

Braun, V., \& Clarke, V. (2019). Reflecting on reflexive thematic analysis. Qualitative Research in Sport, Exercise and Health, 11(4), 589-597. doi: 10.1080/2159676x.2019.1628806

Brown, D. J., Fletcher, D., Henry, I., Borrie, A., Emmett, J., Buzza, A., \& Wombwell, S. (2015). A British university case study of the transitional experiences of student-athletes. Psychology of Sport and Exercise, 21, 78-90. https://doi.org/10.1016/j.psychsport.2015.04.002

BUCS. (2018). FA women's high-performance football centres. Retrieved from https://www.bucs.org.uk/page.asp?section=19666\&search=

Capranica, L., \& Guidotti, F. (2016). Research for cult committee-Qualifications/dual careers in sports. Available from:

http://www.europarl.europa.eu/RegData/etudes/STUD/2016/573416/IPOL_STU(2016)57341 6_EN.pdf

Cartigny, E., Fletcher, D., Coupland, C., \& Taylor, G. (2020). Mind the gap: A grounded theory of dual career pathways in sport. Journal of Applied Sport Psychology. Advance online publication. doi: 10.1080/10413200.2019.1654559

Condello, G., Capranica, L., Doupona, M., Varga, K., \& Burk, V. (2019). Dual-career through the elite university student-athletes' lenses: The international FISU-EAS survey. PLOS ONE, 14(10). doi: 10.1371/journal.pone.0223278

Creswell, J.W. (2013). Qualitative inquiry and research design: Choosing among the five approaches. Thousand Oaks, CA: Sage Publications, Inc.

Day-Garner, J. (2017). Critical transition phases within top-level female football players in Europe: Doctoral Dissertation. Liverpool John Moores University, UK. 
De Brandt, K. (2017). A holistic perspective on student-athletes' dual career demands, competencies and outcomes: Published doctoral dissertation. (SASO; No. 12). Brussels: VUBPRESS.

De Brandt, K., Wylleman, P., Torregrossa, M., Defruyt, S., \& Van Rossem, N. (2017). Studentathletes' perceptions of four dual career competencies. Journal of Sport Psychology, 26(4), $28-33$.

Defruyt, S., Wylleman, P., Kegelaers, J., \& De Brandt, K. (2019). Factors influencing Flemish elite athletes' decision to initiate a dual career path at higher education. Sport In Society, 118. doi: 10.1080/17430437.2019.1669324

Duty of Care in Sport (2017). Duty of Care in Sport Review - Independent Report to Government. Retrieved from https://www.gov.uk/government/uploads/system/uploads/attachment_data/file/610130/Duty_ of_Care_Review_-_April_2017_2.pdf.

European Commission. (2012). EU guidelines on dual careers of athletes: Recommended policy actions in support of dual careers in high-performance sport (pp. 1-40). Retrieved from http://ec.europa.eu/assets/eac/sport/library/documents/dual-career-guidelines-final_en.pdf

Fernandez, A., Stephan, Y., \& Fouquereau, E. (2006). Assessing reasons for sports career termination: Development of the athletes' retirement decision inventory (ARDI). Psychology of Sport and Exercise, 7(4), 407-421. doi: 10.1016/j.psychsport.2005.11.001

Fuchs, P., Wagner, H., Hannola, H., Neimisalo, N., Pehme, A., Puhke, R., ... Guidotti, F. (2016). European student-athletes' perceptions on dual career outcomes and services. Kinesiologia Slovenica, 22(2), 31-48.

Gledhill, A., \& Harwood, C. (2015). A holistic perspective on career development in UK female soccer players: A negative case analysis. Psychology of Sport and Exercise, 21, 65-77. doi: 10.1016/j.psychsport.2015.04.003 
Knight, C., Harwood, C., \& Sellars, P. (2018). Supporting adolescent athletes' dual careers: The role of an athlete's social support network. Psychology of Sport and Exercise, 38, 137-147. doi: 10.1016/j.psychsport.2018.06.007

Larsen, C. H., Alfermann, D., Henriksen, K., \& Christensen, M. K. (2013). Successful talent development in soccer: The characteristics of the environment. Sport, Exercise, and Performance Psychology, 2(3), 190-206. doi: 10.1037/a0031958

Laverty, R. (2018). FA's new dual-career program. Our Game Magazine. Retrieved from https://www.ourgamemag.com/2018/05/24/the-fas-new-dual-career-program/

Levitt, H., Motulsky, S., Wertz, F., Morrow, S., \& Ponterotto, J. (2016). Recommendations for designing and reviewing qualitative research in psychology: Promoting methodological integrity. Qualitative Psychology, 4(1), 2-22. doi: 10.1037/qup0000082

Li, M., \& Sum, R. (2017). A meta-synthesis of elite athletes' experiences in dual career development. Asia Pacific Journal of Sport and Social Science, 6(2), 99-117. doi: $10.1080 / 21640599.2017 .1317481$

Lincoln, Y.S., \& Guba, E.G. (2000). Paradigmatic controversies, contradictions, and emerging confluences. In N.K. Denzin \& Y.S. Lincoln (Eds.), Handbook of qualitative research (2nd ed., pp. 163-188). Thousand Oaks, CA: Sage.

Lo Iacono, V., Symonds, P., \& Brown, D. (2016). Skype as a tool for qualitative research interviews. Sociological Research Online, 21(2), 1-15. doi: 10.5153/sro.3952

Lupo, C., Guidotti, F., Goncalves, C. E., Moreira, L., Doupona Topic, M. D., Bellardini, H., ... Capranica, L. (2015). Motivation towards dual career of European student-athletes. European Journal of Sport Science, 15, 151-160. doi: 10.1080/17461391.2014.940557

MacNamara, Á., \& Collins, D. (2010). The role of psychological characteristics in managing the transition to university. Psychology of Sport and Exercise, 11(5), 353-362. https://doi.org/10.1016/j.psychsport.2010.04.003 
McCormack, C., \& Walseth, K. (2013). Combining elite women's soccer and education: Norway and the NCAA. Soccer \& Society, 14(6), 887-897. doi: $10.1080 / 14660970.2013 .843927$

Meyer, S. (2005). NCAA academic reforms: Maintaining the balance between academics and athletics. Phi Kappa Phi Forum, 85(3), 15-18.

NCAA. (2018). How we support college athletes. Retrieved from http://www.ncaa.org/about/resources/media-center/ncaa-101/how-we-support-collegeathletes

O’Neill, M., Allen, B., \& Calder, A. (2013). Pressures to perform: An interview study of Australian high performance school-age athletes' perceptions of balancing their school and sporting lives. Performance Enhancement \& Health, 2(3), 87-93. doi: 10.1016/j.peh.2013.06.001

Oltmann, S. (2016). Qualitative interviews: A methodological discussion of the interviewer and respondent contexts. Forum: Qualitative Social Research, 17(2), 15-21.

Patton, M. (2002). Qualitative research and evaluation methods (3rd ed.). Thousand Oaks, CA: Sage.

Reints, A. (2011). Validation of the holistic athletic career model and the identification of variables related to athletic retirement. Brussels: Vubpress.

Ryba, T., Stambulova, N., Ronkainen, N., Bundgaard, J., \& Selänne, H. (2015). Dual career pathways of transnational athletes. Psychology of Sport and Exercise, 21, 125-134. doi: 10.1016/j.psychsport.2014.06.002

Shenton, A. (2004). Strategies for ensuring trustworthiness in qualitative research projects. Education For Information, 22(2), 63-75. doi: 10.3233/efi-2004-22201 
Shultz, K., Morton, K., \& Weckerle, J. (1998). The influence of push and pull factors on voluntary and involuntary early retirees' retirement decision and adjustment. Journal of Vocational Behavior, 53(1), 45-57. doi: 10.1006/jvbe.1997.1610

Sparkes, A., \& Smith, B. (2014). Qualitative research methods in sport, exercise and health (1st ed.). Oxon: Routledge.

Sporting Intelligence. (2017). Global sports salaries survey 2017. Retrieved from http://globalsportssalaries.com

Stambulova, N. B., Engström, C., Franck, A., Linnér, L., \& Lindahl, K. (2015). Searching for an optimal balance: Dual career experiences of Swedish adolescent athletes. Psychology of Sport and Exercise, 21, 4-14. doi: 10.1016/j.psychsport.2014.08.009

Stambulova, N., \& Wylleman, P. (2019). Psychology of athletes' dual careers: A state-of-the-art critical review of the European discourse. Psychology of Sport and Exercise, 42, 74-88. https://doi.org/10.1016/j.psychsport.2018.11.013

Swann, C., Moran, A., \& Piggott, D. (2015). Defining elite athletes: Issues in the study of expert performance in sport psychology. Psychology of Sport and Exercise, 16, 3-14. doi: 10.1016/j.psychsport.2014.07.004

TASS. (2019). TASS accreditation. Retrieved from https://www.tass.gov.uk/about/accreditation/ Tekavc, J., Wylleman, P., \& Cecić Erpič, S. (2015). Perceptions of dual career development among elite level swimmers and basketball players. Psychology of Sport and Exercise, 21, 27-41. doi: 10.1016/j.psychsport.2015.03.002

The FA. (2017). Educating England: England's player education manager reflects on culture change. Retrieved from http://www.thefa.com/news/2017/11/22/12/22/caitlin-hawkinsplayer-education-manager-england-development-teams-221117

Tracy, S. (2010). Qualitative quality: Eight "big-tent" criteria for excellent qualitative research. Qualitative Inquiry, 16(10), 837-851. doi: 10.1177/1077800410383121 
Vickers, E. (2018). An examination of the dual career pathway and transitions UK studentathletes experience throughout university education: Doctoral dissertation. Liverpool John Moores University, UK.

Vogl, S. (2013). Telephone versus face-to-face interviews: Mode effect on semi-structured interviews with children. Sociological Methodology, 43(1), 133-177. doi: $10.1177 / 0081175012465967$

Wylleman, P., De Brandt, K., \& Defruyt, S. (2017). Gold in education and elite sport: Handbook for dual career support providers. Retrieved from http://www.gees.online

Wylleman, P., \& Lavallee, D. (2004). A developmental perspective on transitions faced by athletes. In M. Weiss (Ed.), Developmental sport and exercise psychology: A lifespan perspective (pp.503-523). Morgantown, WV: Fitness Information Technology.

Wylleman, P., \& Rosier, N. (2016). Holistic perspective on the development of elite athletes. In M. Raab, P. Wylleman, R. Seiler, A. M. Elbe, \& A. Hatzigeorgiadis (Eds.), Sport and exercise psychology research: From theory to practice (pp. 269-288). London: Elsevier. 